\title{
Leucodepletion and Blood Products
}

\author{
Col Harsh Kumar, Lt Col PK Gupta ${ }^{+}$, Lt Col DK Mishra\#, Lt Col RS Sarkar ${ }^{* *}$, Brig M Jaiprakash ${ }^{++}$
}

\begin{abstract}
Background : Leucoreduction of blood products is increasingly being employed to produce blood products with residual WBCs < $5 \times 10^{6}$ per unit (99.9 percent or a $\log 3$ leucoreduction). Clinical data suggests that non-haemolytic febrile transfusion reactions can be prevented by leucodepletion. The procedure also prevents alloimmunisation to HLA antigens in patients who will repeatedly require transfusion of blood/blood products.

Method : Of the methods available to reduce the number of WBC in blood products washing of red cells, freezing and deglycerolisation are effective and yield a product with only a 24 hour shelf life. Other methods such as leucodepletion filters are relatively inexpensive, simple and the final product has a normal shelf life. Modern generation of leucoreduction filters and apheresis machines can provide greater than $4 \log$ reduction of WBC.

Results : After the introduction of leucodepletion of blood for Thalassemics at our center in 2003, the incidence of non haemolytic febrile transfusion reactions (NHFTR) fell from $4 \%$ in 2002 to $1 \%$ in 2003.

Conclusion : In patients undergoing long-term blood transfusion therapy e.g. Thalassemics, alloimmunisation against the HLA antigens on donor white cells is prevented by leucodepletion and prevents NHFTRs.
\end{abstract}

MJAFI 2006; 62 : 174-177

Key Words : Leucoreduction; leucodepletion; alloimmunisation.

\section{Introduction}

$\mathrm{L}$ eucodepletion is a process by which leucocytes are removed from donated blood. It has been estimated that the average content of leucocytes in donated human whole blood is $10^{9} /$ unit. By the current standards, the total content leucocytes in a blood unit should be less than $5 \times 10^{6}$ unit after preparation and a minimum of $85 \%$ of whole blood or red cells is retained [1]. This process has been in use for some time for a select group of patients e.g. the multi-transfused patients, the immunocompromised and malignancy patients. It has been well established that febrile reactions occuring in most cases while transfering blood is due to immune reaction of the recipient against donor leucocytes [2]. The original leucocyte depletion filter contained cotton wool as the filtering agent and was designed by Diepenhorst who published his work in 1972 [3]. Subsequently, cellulose acetate filters were discovered and found to be more suitable. Other methods include red cell washing, centrifugation and buffy coat removal, freezing and deglycerolisation of red cells and apheresis $[4,5]$. The initial standards for leucodepletion required removal of at least $70 \%$ white blood cells and retention of $70 \%$ of the original red cells [4]. These values have been under review constantly, and presently, blood is considered leucodepleted if the total leucocyte content per unit of blood is $<5 \times 10^{6}$ and the red cell product should have retained at least $85 \%$ of the original red cells [4].

It has been observed that antibodies against histocompatibility antigents tend to develop in the recipient, if the leucocyte content in a unit of transfused blood exceeds the figure stated above. The same observation has been made with respect to WBCs contaminating units of platelet concentrates. The current consensus is that, antigens on the platelets, by themselves are not capable of initiating a primary immune response. However, even with their weaker antigenic capability they can propogate a secondary immune response [6]. Therefore to avoid primary alloimmunisation against the histocompatability antigens, the total content of leucocytes in a unit of red cells should be less than $5 \mathrm{x}$ $10^{6}$ per unit. To qualify as leukocyte reduced platelets, pheresis units should also have less than $5 \times 10^{6}$ leukocyte per bag. For platelet concentrates derived from whole blood, the standard requires that each unit contains no more than $0.83 \times 10^{5} \mathrm{WBC}$ per unit, so that a pool of six units would contain no more than $5 \times 10^{6} \mathrm{WBC}$ per unit [7].

\section{Leucocyte antibodies}

The role of leucocyte antibodies in causation of

"Prof and Head, ${ }^{+}$Assoc Prof, Dept of Transfusion Medicine, AFMC, Pune. ${ }^{\# C l a s s i f i e d ~ S p e c i a l i s t ~(P a t h o l o g y ~ a n d ~ H a e m a t o l o g y), ~ A H ~(R \& R), ~}$ Delhi Cantt. ${ }^{* *}$ Classified Specialist(Pathology), MH Roorkee. ${ }^{++}$Dy Comdt, CH(SC), Pune.

Received : 10.11.2004; Accepted : 26.09.2005 
transfusion reactions was suggested while observing better tolerance of leucocyte poor blood by patients who had a history of severe febrile reactions following blood transfusions [2,8]. The patients characteristically had flushing and a feeling of warmth shortly following transfusion. Subsequently, the patients felt better for a period varying between $40-60$ minutes before developing a severe febrile reaction. Antibodies produced consequent to alloimmunisation, may react both with the HLA antigens and granulocyte specific antigens. In a study, sera from 101 patients presenting with a history of non haemolytic transfusion reactions, reacted strongly against leucocytes [9]. In another study, it was observed that HLA antibodies were found frequently than granulocyte specific antibodies. Alloantibody of one kind or the other was found in every single case [10].

Platelet products invariably get contaminated with leucocytes. It is unfortunate, that 30 to 50 percent of patients who receive multiple platelet transfusions become alloimmunised to HLA antigens, and subsequently do not respond to pooled random donor platelets and become platelet refractory [11]. Therefore, prevention of transfusion induced HLA alloimmunization could be of significant benefit in transfusion medicine. Formation of antibodies against histocompatibility antigens occurs if platelets are contaminated with leucocytes. Platelets per se, alone are only capable of inducing a secondary immune response. The induction of a primary immune response is dependant on the presentation of foreign class I antigens by transfused white blood cells [12]. It therefore implies that, alloimmunization against class I antigens can be prevented by leucodepletion of platelet concentrates. There is ample evidence that primary HLA immunization does not occur when less than $5 \times 10^{6}$ leucocytes per unit are transfused [6]. This value also applies to simple whole blood, the value is $<8.3 \times 10^{5}$ in all bags. Since the final pooled component also must have $5 \times 10^{6}$ leucocytes. This implies that the final pool size should not exceed 6 units [1].

\section{Preparation methods}

Various methods have been employed for leucodepletion of blood. A clear distinction can be made into two types.

1. An open system of leucocyte removal where the closed system is entered as a consequence of which the blood unit has a shelf life of only 24 hours. e.g.. manual and automated cell washing, freezing and de-glycerolisation of red cells.

2. A closed system, wherein, the normal shelf life of the blood / blood product is maintained. Here the processing for leucodepletion is done without entering the original blood collection pack or with entry of the system only during the course of transfusion e.g. centrifugation and buffy coat removal.

i) Cell washing-Cell washing done by automated machines or manual methods, removes not only the leucocytes, but also the plasma. The automated systems are also very expensive and washed red cells have a shelf life of only 24 hours.

ii) Centrifugation and buffy coat removal- After packing, red cells are subjected to visually controlled expression of the buffy coat using a plasma expresser. In this technique, leucodepletion is proportional to red cell loss, with a cut off point subjective to each operator. This method has therefore lost its popularity. The only virtue of this method is that it is a closed system [13].

iii) Freezing and Deglycerolisation- Glycerol serves as a cryo-protectant, and is added to packed red cells. These cells are then frozen to $-60^{\circ} \mathrm{C}$ or below for storage. Both glycerolization and freezing destroys the leucocytes. After the red cells are thawed, the glycerol is removed by washing [14].

iv) Leucocyte filters - The leucocyte removal filters contain multiple layers of synthetic polyester nonwoven fibres that selectively retain white cells while allowing red cells and / or platelets to flow through. Lymphocytes and monocytes are passively held in the filter, while granulocytes in addition are also trapped by adhesion [15]. Filters are less expensive as compared to other methods as automated cell washing, freezing and de-glycerolisation. It has therefore emerged as an effective and reliable way for leucodepletion [13]. Advances in filtration techniques and type of filters have resulted in reducing WBCs in red cell and platelet concentrates to 99.9 percent (less than $5 \times 10^{6} \mathrm{WBC}$ per unit) and more [16-18].

Leucocyte filters are available commercially in a number of configurations. They can be used to perform leucodepletion before storage (on-line leucodepletion), or in the laboratory (pre-storage) or it may even be carried out at the bedside during blood transfusion. The timing of leucodeption is important. It is well known that leucocyte removal is better if the time span between blood collection and leucodepletion is shortened. This is so because, during storage, leucocytes degranulate, fragment or die thereby releasing their contents that could result in febrile and allergic transfusion reactions. The cytokines especially IL-8 that accumulate during storage have been implicated for some failures of bedside filtration to prevention febrile reaction [18]. 


\section{Counting Methods}

Special methods of cell counting are required to detect such a low number of leukocytes in leucocyte depleted blood. Automated haematology cell counting devices may not accurately determine the residual leukocytes in leukocyte-reduced products. The methods used are as follows-

Manual methods - Methods using Nageotte counting chamber and Turk's or Plaxan's staining solutions alone or in conjunction with Zap-oglobin ${ }^{\circledR}$ or centrifugation are comparable in sensitivity and reliability for counting less than 5 leukocytes/uL [17-20].

Automated methods - Flow cytometry, using propidium iodide alone or combined with thiazole orange, compares favourably in sensitivity to the Nageotte chamber method and provides the advantages of automation and the ability to determine phenotypes of residual leukocytes which may be of interest to clinicians [21].

\section{Indications for leucodepleted transfusion}

Leucodepletion is generally indicated in-

a) Reduction of non-haemolytic transfusion reactions.

b) Reduction of HLA alloimmunisation that may lead to patients becoming refractory to platelet transfusions e.g. patients requiring long term platelet therapy as in Aplastic anaemia and MDS.

c) Reduction of CMV transmission e.g. in patients awaiting organ transplantation.

d) Reduction in the risk of Yersinia enterocolitica contamination of RBC.

e) Possible reduction of Prion Disease.

f) Reduction in the incidence of transfusion associated GVHD (TA-GVHD).

\section{Efficacy of leucocyte filters}

Various trials for validating the efficacy of leucocyte filters have been carried out. The leucocyte filters currently available are capable of providing the desired level of leucodepletion. Present day filters provide a minimum of $3 \mathrm{log}$ depletion of WBC and many filters are commercially available which can provide $4 \mathrm{log}$ depletion and more [22-23]. It has been observed that loss of red cells while filtering blood ranges from $30-$ $65 \mathrm{ml}$ depending from filter to filter and about 12 to 14 percent of the platelets are also lost. The losses are more when packed red cells in CPDA are filtered visà-vis packed red cells in Adsol/SAGM. The product loss during filtration of Single Donor Platelets (SDP) can range to anything form 45 to $50 \mathrm{ml}$. Leucodepletion filters for platelets are different as they are supposed to retain platelets during filtration. Unfortunately, the loss of platelets during this procedure has been reported to be anything from 9 to 35 percent. This is quite high and may result in an increased frequency of transfusions and donor exposures to compensate for the loss during processing [24]. The time taken for filtration varies from filter to filter and can take anything from 10 to $20 \mathrm{~min}$. Current generation of apheresis machines and disposable sets used are capable of achieving a $3 \log$ leucodepletion, obviating the need for filtration [25-26].

\section{Our experience at Dept of Transfusion Medicine, AFMC.}

Current therapy for thalassemia syndromes consists of regular red cell transfusions to maintain a baseline hemoglobin level $>9 \mathrm{~g} / \mathrm{dl}$, coupled with intensive parenteral chelation therapy with desferoxamine. These patients receive long-term multiple transfusion and the common transfusion reactions noted are non-haemolytic febrile transfusion reaction (NHFTR) and allergic reactions. Others include iso-immunisation, autoimmune haemolytic anaemia proven with circulating autoantibodies, posttransfusional hypertension, etc. [27]. In our center, since 2003, leucodepletion of blood is routinely being done using third generation pre-storage filters (PALL, USA) before transfusion to thalassemias. Of the 303 transfusions given to Thalassemics, in 2003, only 03 patients $(1 \%)$ had NHFTR after use of leucodepleted blood in comparison to 10 out of 252 (4\%) in 2002 who received non-leucodepleted blood. All units of blood were tested for pre and post leucoreduction WBC count. The requisite standard of leucoreduction were achieved $(\mathrm{p}<0.001)$.

\section{Conclusion}

Leucocyte removal from blood components before transfusion by leucocyte depletion filters is known to prevent or at least delay leucocyte mediated adverse reactions. By use of third generation leucodepleted filters, the WBC count in the red cell and platelet concentrates has reduced to greater than $99.9 \%$. The increasing use of leucocyte-depleted products increases the need for quality assurance. The American standards specify that leucodepleted blood should have less than 5 $\mathrm{x} 10^{6}$ WBC per unit of blood. Food and Drug administration guidelines (FDA) recommend testing of $1 \%$ of leucodepleted units of which 100 percent should contain less than $5 \times 10^{6} \mathrm{WBC}$ per unit of blood. It is to be noted that quality control procedures cannot be carried out satisfactorily on bedside leucodepletion filters and therefore bedside leucodepletion should only be carried out when other options for leucodepletion cannot be utilized. Universal leucodepletion is the best method in transfusion practice, but in developing countries like ours, it is not cost effective. To conclude, the aim should be 
to constantly prepare WBC reduced blood products with less than $5 \times 10^{6}$ residual $\mathrm{WBC}$ so that primary alloimmunisation to HLA antigens is prevented and transfusion is made safer.

\section{Conflicts of Interest}

None identified

\section{References}

1. Tayler VV. Editor. Technical Manual. AABB. $13^{\text {th }}$ edition. Mayland, USA. 1999, 175-6.

2. Perkins HA, Payne R, Fergusson J, Wood M. Non Haemolytic transfusion reactions. Quantitative effects of blood components with emphasis on isoantigenic incompatibility of leucocytes. Vox Sang 1966; 11: 578-600.

3. Diepenhorst P, Engelfriet CP. Removal of leucocytes from whole blood and erythrocyte suspensions by filterations through cotton wool. V, Results after transfusion of 1,820 units of filtered erythrocytes. Vox Sang 1975; 29: 15-8.

4. Novotny VMJ, van Doorn R, Witvliet MD et al. Occurrence of allogenic HLA and non HLA antibodies after transfusion of prestorage filtered platelets and red blood cells : A prospective study. Blood 1995; 85: 1736-41.

5. Kientz D, Laforet M, Isola H, Cazenave JP. Leukodepletion of platelet concentrates and plasma collected with haemonetics MCS+ apheresis system. Experience of EFS-Alsace. Transfus Apheresis Sci 2001: 25; 55-9.

6. Claas FHJ, Smeenk RJT, Schmidt R et al. Alloimmunisation against MHC antigens after platelet transfusions is due to contaminating leucocytes in the platelet suspension. Exp Hemat 1981; 9: 84-9.

7. Menitove JE. Ed. Standards for blood banks and transfusion services. $19^{\text {th }}$ ed. Bethesda MD: Am Assocn of Blood Banks: 1999.

8. Pruss A, Kalus U, Radtke H, Koscielny J, Bsumsnn-Zbaretti B, Balzer Universal Luekodepletion of blood components results in a significant reduction of febrile non-hemolytic but not allergic transfusion reactions. Transfus Apheresis Sci. 2004; 30: 41-6.

9. De cary F, Ferner P, Giavedoni L et al. An investigation of non haemolytic transfusion reactions. Vox Sang 1984; 46: 227-85.

10. De Rie MA, Van der plas-van Dalen CM, Engelfriet CP et al. The serology of febrile transfusion reactions. Vox Sang 1985; 49: 126-34.

11. Howard JE, Perkins HA. The natural history of alloimmunisation to platelets. Transfusion. 1978; 18: 496-503.

12. Sherwood RA, Brent L, Rayfield LS. Presentation of alloantigens by host cells. Eur J Immunol 1986; 16: 574-96.
13. Begue S. Leukocyte depletion. Transfus Clin Biol. 1998; 5: 411-4.

14. Meryman HT, Hornblower M. A method for freezing and washing red cells using a high glycerol concentration. Transfusion 1972; 12: 145-56.

15. Dzik S. Leucodepletion filters: Filter design and mechanisms of leucocyte removal. Trans Med Rev 1993; 7: 65-77.

16. Buchholz DH. AuBuchon JP, Snyder EL, et al. Effects of white cell reduction on the resistance of blood components to bacterial multiplication. Transfusion 1994; 34: 852-7.

17. Rubella P, Dzik W. Multicenter evaluation use of the Nageotte haemocytometer to count low levels of white cells in white cell-reduced platelet products. Transfusion 1994; 35: 35-8.

18. Lutz P, Dzik W. Large-volume hemocytometer chamber for accurate counting of white cells (WBCs) in WBC reduced platelets: Validation and application for quality control of WBCreduced platelets prepared by apheresis and filtration. Transfusion 1993; 33: 409-12.

19. Muller TH, Doscher A, Schunter F, Scott CS. Manual and automated methods for the determination of leukocyte counts in extreme low levels: comparative evaluation of the Nageotte chamber and the Abbott Cell Dyn 3500 analyser. Transfus Sci.1997; 18: 505-15.

20. Rubella O, Porretti F, Bertolini FM et al. white cell-reduced cell prepared by filteration: a critical evaluation of current filters and methods for counting residual white cells. Transfusion 1993; 33: $128-33$.

21. Dzik WH, Ragosta A, Cusak WF. Flow-cytometric method for counting very low numbers of leukocytes in platelet products. Vox Sang 1990; 59: 153-9.

22. Bodenstiener DC. Leucocyte depletion filters: a comparision of efficiency. Am J Hematol 1990; 35: 184-6.

23. Bontadini A, Fruer F, Conte R. A new tool in white cell blood reduction for packed red cells: 5 log depletion. Transfus Med 1997; 7: 29-32.

24. Miyamoto M, Sasakawa S Ishikawa Y, Ogawa A, Nishimura T, Kurudo T. Leucocyte poor platelet concentrates at the bedside filtration by filtration through Sepacell- PL Vox Sang 1989; 57 : 164-7.

25. Riverberi R, Menini C. Clinical efficacy of five filters specific for leucocyte removal. Vox Sang 1990; 58: 188-91.

26. Dzik S, Aubuchon J, Jeffries L et al. Leucocyte reduction of blood components: public policy and new technology. Transfusion Medicine Reviews 2000; 14: 34-52.

27. Constantopoulos A, Matsaniotis N. Hypertension, convulsion and cerebral hemorrhage in thalassemic patients after multiple blood transfusions. Helv Paediatr Acta. 1980; 35: 269-73. 